\title{
Early Marriage in Girls 12 - 18 Years: Frequency and Predisposing Factors in the City of Kabinda, Province Lomani/DRC Congo
}

\author{
Adeline Kasanj Kalum', Daniel Kitambo Kabiengele², Dieudonne Lumanu Mposhi'3, \\ Regine Nkusu Kalenga4, Bertin Mpaka Mpaka5, Mediatrice Kasheta Mabondo5, Kalala Odia5, \\ Ennock Mbuyi Kabeya', Valentin Kabambi Bukasa6, Emmanuel Mpetemba Mubala7, \\ Jean Christophe Bukasa Tshilonda ${ }^{*}$
}

\author{
${ }^{1}$ Higher Pedagogical Institute of Kabinda, Kabinda, Democratic Republic of the Congo \\ ${ }^{2}$ Higher Institute of Agronomic Studies and Veterinary Lukashi, Kabinda, Democratic Republic of the Congo \\ ${ }^{3}$ Highter Institute of Medical Techniques of Lubao, Lubao, Democratic Republic of Congo \\ ${ }^{4}$ Higher Institute of Medical Techniques of Kindu, Kindu, Democratic Republic of the Congo \\ ${ }^{5}$ Higher Institute of Medical Techniques of Kabinda, Kabinda, Democratic Republic of the Congo \\ ${ }^{6}$ Higher Institute of Medical Techniques of Mbujimayi, Mbujimayi, Democratic Republic of the Congo \\ ${ }^{7}$ Higher Institute of Medical Techniques of Miabi, Miabi, Democratic Republic of the Congo \\ Email: ${ }^{* j c b u k a s a 4 @ g m a i l . c o m ~}$
}

How to cite this paper: Kalum, A.K., Kabiengele, D.K., Mposhi, D.L., Kalenga, R.N., Mpaka, B.M., Mabondo, M.S., Odia, K., Kabeya, E.M., Bukasa, V.K., Mubala, E.M. and Tshilonda, J.C.B. (2019) Early Marriage in Girls 12 - 18 Years: Frequency and Predisposing Factors in the City of Kabinda, Province Lomani/DRC Congo. Open Access Library Journal, 6: e5268. https://doi.org/10.4236/oalib.1105268

Received: February 20, 2019

Accepted: June 25, 2019

Published: June 28, 2019

Copyright $\odot 2019$ by author(s) and Open Access Library Inc.

This work is licensed under the Creative Commons Attribution International License (CC BY 4.0).

http://creativecommons.org/licenses/by/4.0/

(c) (i) Open Access

\begin{abstract}
Introduction: To determine the frequency and risk factors of early marriage among girls $12-18$ years in the city of KABINDA. Material and methods. This study is descriptive cross. It was conducted in 5304 households in two Kamukungu health areas and Kilo located KAMUKUNGU neighborhood. The sample consisted of 1227 women of childbearing age, married at an early stage that had been subjected to a questionnaire that was used as data collection tool. Results: The early marriage rate among girls $12-18$ years is $23.1 \%$. Factors encouraging this early marriage are poverty (continued to unemployed parents, resourceful and load carriers) (33.9\%), culture and custom (31.4\%), family and social pressure (17.9\%) and non-use of contraceptive methods (17.2\%). Conclusion: Early marriage in our communities is an all too common phenomenon in the DRC in general and particularly in the province of South Kivu, or one in four women currently aged $40-45$ had married before the age of 18 . This is also the situation in the province of Lomani and precisely in the city of KABINDA. To do this, it would popularize laws and legal texts on the protection of children especially in education, and marriage continues to raise awareness of the city of KABINDA and prevent child marriage by bringing to 18 , the minimum age for marriage and support oriented programs to protect and promote the
\end{abstract}


rights of adolescent girls.

\section{Subject Areas}

Psychology, Sociology

\section{Keywords}

Early Marriage, Frequency, Factors Favoring Teenager

\section{Introduction}

Worldwide, the majority of teenage pregnancies are married and their entourage insists they have a child. These may too early and unwanted pregnancy because they are marginalized, uneducated, married early or they belong to poor families [1].

According to the WHO [2], almost 16 million girls aged 15 to 19 years and some 1 million young people aged under 15 give birth to children each year and most live in low-income countries or intermediate, in poor, low education or rural. For SCATE AFRICA/APF [3], nearly 112 of the world's births still occur among girls 15 to 19 years. The teenage pregnancy remains a major killer of the mother and child and contributes to the cycle of poor health and poverty [4]. In some countries extramarital pregnancies are rare, girls often experience social pressure to marry and have children early. Some teens do not know how to prevent pregnancy that sex education is lacking in many countries. They sometimes ashame or do not dare to resort to contraceptive services because contraceptives are too expensive or are widely and legally unavailable, and sexually active adolescents are less likely to use them [5].

In Africa, early marriage problem arises with acuity. A study in Burkina by INSD and UNICEF in 2006, reveals that women whose age range is between 15 to 19 years, numerous of these, $25 \%$ are cohabiting $30.9 \%$ of them living in rural and urban $9.5 \%[6]$.

According to the study report "DHS IV and NEA" cited by KELLY FATOUMATA DJIRE [7], it reveals that the evolution of early marriage rate in MALI is on track to be widespread in urban areas than in rural area. In the region of Mopti and GAO, about 75\% of marriages are between 9 and 17 years. In Timbuktu, the rate was $58.3 \%$ with early between 8 and 17 years. The same source shows some causes more detail including certain religions "encourage" marriage at the onset in the early rules, precocious puberty, strengthening family ties, friendship and neighborhood, saving the virginity of the girl and the honor of the family, low education of girls, positive values assigned to procreation, the lack of information on the risks associated with early marriage, poverty.

In the Democratic Republic of Congo, early marriage among girls is a scourge and is a real public health problem because according to a study by BASEDEKE. A. [8], early marriage in our communities is an all too common phenomenon in 
the DRC in general and particularly in the province of South Kivu, or one in four women currently aged 40 - 45 had married before the age of 18 . In this study, the following causes of early marriage were among others: blind imitation (want to do as the other girls), early pregnancy, influence of some parents ... This type of marriage has serious consequences for the adolescent's health, in particular: the girl's growth stoppage, divorce, family instability, marital infidelity, polygamy, polyandry, the disruption of the girl's health. daughter education etc..

In Kabinda, capital of the new province of Lomani dismembered but still rural, cases of early marriage were perceptible. This observation has led us to conduct this study.

\section{Material and Method}

This study is a descriptive cross. It was conducted in 5304 households in two Kamukungu health areas and Kilo located KAMUKUNGU neighborhood. The sample consisted of 1227 women of childbearing age, married early.

\section{Results}

Table 1 shows that the early marriage rate among girls 12 - 18 years is $23.1 \%$.

Table 2 shows that the age of 15 years is the most affected by the phenomenon of early marriage is $25.6 \%$.

Table 3 shows that girls born to farmer parents marry so quickly or $28.8 \%$ against $18.7 \%$ from the family of resourceful parents.

In light of Table 4, poverty (continued to unemployed parents, resourceful and load carriers) is deemed one cause of early marriage among girls, with 506

Table 1. Frequency of cases of early marriage in the city of KABINDA.

\begin{tabular}{ccc}
\hline Case & Not & $\%$ \\
\hline Married before age 18 & 1227 & 23.1 \\
Married after 18 years & 4077 & 76.9 \\
TOTAL & 5.304 & 100
\end{tabular}

Table 2. Distribution of cases of early marriage age.

\begin{tabular}{ccc}
\hline AGE IN YEAR & Not & $\%$ \\
\hline 12 & 2 & 0.16 \\
13 & 48 & 3.91 \\
14 & 243 & 19.9 \\
15 & 315 & 25.9 \\
16 & 186 & 15.1 \\
17 & 222 & 18.1 \\
18 & 211 & 17.1 \\
TOTAL & 1227 & 100 \\
\hline
\end{tabular}


Table 3. Distribution of cases of early marriage by occupation of household charge.

\begin{tabular}{cccc}
\hline NOT & PROFESSION & Not & $\%$ \\
\hline 01 & Farmers & 354 & 28.9 \\
02 & Resourceful & 230 & 18.7 \\
03 & Pro Health (Doctor/Nurse) & 42 & 3.4 \\
04 & Teachers & 204 & 16.6 \\
05 & State officials & 121 & 9.9 \\
06 & Load carrier & 103 & 8.4 \\
09 & Unemployed & 173 & 14.1 \\
& TOTAL & 1227 & 100 \\
\hline
\end{tabular}

Table 4. Distribution of cases of early marriage as factors favoring.

\begin{tabular}{cccc}
\hline NOT & Contributing factors & Not & $\%$ \\
\hline 01 & Poverty (unemployed parents, resourceful & 506 & 41.2 \\
& and load carriers) & & \\
02 & Culture and custom & 386 & 31.4 \\
03 & Family and social pressure & 213 & 17.3 \\
04 & Rape & 63 & 5.13 \\
05 & No contraceptive use & 220 & 17.9 \\
06 & Sex education missed orphanage & 17 & 1.38 \\
& TOTAL & 1227 & 100 \\
\hline
\end{tabular}

cases in 1227 or $33.9 \%$ are followed by culture and custom with 386 cases or $31.4 \%$ of cases, family and social pressure and the non-use of contraceptive methods with 220 cases, respectively $17.9 \%$ and 213 cases or $17.2 \%$.

Table 5 shows that 680 girls married early $55.4 \%$ had reached the level of secondary education, against 472 or $38.4 \%$ have a primary level of study.

It appears from Table 6 that 576 girls married early $46.9 \%$ are in the polygamous marriage against 483 cases or $39.4 \%$ are monogamous.

\section{Discussion}

\subsection{Early Marriage Rate}

The frequency of early marriage among girls $12-18$ years is $23.1 \%$. This result agrees with the statement of UNFPA [9] confirming that "year worldwide, the majority of teenage pregnancy are married and their entourage insists they have a child."

\subsection{The Age of Early Marriage}

In this study 2 girls on 1227 or $0.6 \%$ were married early at the age of 12 years and 315 girls $25.6 \%$ are married and 15 years. these results are similar to those of the study by UNFPA [9] which showed that over $30 \%$ of girls in developing countries are married before the age of 18 ; about $14 \%$ are married before age 15 
Table 5. Distribution of cases of early marriage by level of education.

\begin{tabular}{cccc}
\hline NOT & EDUCATIONAL LEVEL & Not & $\%$ \\
\hline 01 & Primary & 472 & 38.4 \\
02 & Secondary & 680 & 55.4 \\
03 & Without level & 75 & 6.2 \\
& TOTAL & 1227 & 100 \\
\hline
\end{tabular}

Table 6. Distribution of cases of early marriage as forms of marriage.

\begin{tabular}{cccc}
\hline NOT & FORM OF MARRIAGE & Not & $\%$ \\
\hline 01 & Monogamous & 483 & 39.4 \\
02 & Polygamous & 576 & 46.9 \\
03 & Free Union & 168 & 13.7 \\
& TOTAL & 1227 & 100 \\
\hline
\end{tabular}

years. Early marriage is a risk factor for early pregnancy and cause adverse reproductive health. In addition, early marriage extends the cycle of under education and poverty.

\subsection{Level of Education}

In relation to education, 680 girls married early $55.4 \%$ had reached the level of secondary education, against 472 or $38.4 \%$ have a primary level of study. These results contradict those of JESSAMINEMariam. M's study [10], which indicated that the occurrence of unwanted teenage pregnancies is partly explained by a context marked by a pronounced low education, aided by the natalist tradition also pushing for an early marriage.

\subsection{Job of Household and Responsible Factors Favoring Early Marriage}

Girls born to farmer parents marry so quickly or $28.8 \%$ against $18.7 \%$ from resourceful parents. Compared to promoting factors, poverty is deemed cause of early marriage among girls, with 506 cases in 1227 or $33.9 \%$ is followed by culture and custom with 386 cases or $31.4 \%$ of cases. These results are compared with data from the National Strategic Plan for 2014-2020 multisectoral vision) demonstrating that the DRC is characterized by a high prevalence of poverty is estimated at $71 \%$ in 2005 . WHO/UNFPA [11] Adds that poverty is a factor that is often used to explain the phenomenon of early marriage.

\section{Conclusion}

Early marriage in our communities is an all too common phenomenon in the DRC in general and particularly in the province of South Kivu, or one in four women currently aged 40 - 45 had married before the age of 18 . This is also the situation in the province of Lomani and specifically in the town of KABINDA. To do this, it would popularize laws and legal texts on the protection of children 
especially in education, and marriage continues to raise awareness of the city of KABINDA and prevent child marriage by bringing to 18 , the minimum age for marriage and support oriented programs to protect and promote the rights of adolescent girls.

\section{Conflicts of Interest}

The authors declare no conflicts of interest regarding the publication of this paper.

\section{References}

[1] EDSM IV and NEA (2017) Early Child Marriage Must Be Stopped: A Disastrous Record of Our Humanity. 35.

[2] WHO (2012) Weddings Precocious, Teenage Pregnancies in the Girls and the March 16.

[3] SCATE AFRICA/APF (2013) Early Marriage Destroys Girls: Madagascar. 10.

[4] Apeflhelbling, R. (2005) Forced Marriage and Child Marriage: Parliamentary Assembly. Swiss June, 20.

[5] Project (2009) Eliminating Child Marriage FASO: A Plan for the Protection and Strengthening Action, Community. FASO, 13.

[6] UNICEF/FABULA Association: International Association for Health of Women (2008) Early Marriage until My Death Do Us; Understand the Risk of Early Marriage for Sexual and Reproductive Health, Canada.

[7] Djire, K.F. (2014) The Teen Pregnancy. Fact No. 364 Updated in September. http://www.gyneco-ledigabel.fr

[8] Basedeke, A.T. (2014) The Government Is Committed in the Fight against School-Based Pregnancy, Togo.

[9] UNFPA (2013) Maternal, Newborn, Child and Teen. http://www.who.int/maternal child adolescent/fr/index.html

[10] Jessamine (2011) Memory, Wedding Girls in Morocco. 34.

[11] WHO/UNFPA (2016) Early Marriage, Teenage Pregnancy and Young Girls. Fact Sheet No. 364. Submitted to the 65th World Health Assembly. 